\title{
Acculturation in Human Culture Interaction - A Case Study of Culture Meaning in Cultural Product Design
}

\author{
Ya-Juan Gao1, Weichen Chang2, Wen-Ting Fang1 and Rungtai Lin ${ }^{1 *}$ \\ ${ }^{1}$ Graduate School of Creative Industry Design, National Taiwan University of Arts, \\ Taiwan
}

2Department of Industrial Design, Chang Gung University, Taiwan

\section{Review Article}

Volume 2 Issue 1

Received Date: January 19, 2018

Published Date: January 26, 2018

DOI: $10.23880 /$ eoij- 16000135

*Corresponding author: Rungtai Lin, Professor, Graduate School of Creative Industry Design, National Taiwan University of Arts, 59,Sec. 1, Daguan Rd., Banqiao Dist., New Taipei City, Taiwan, Email: rtlin@mail.ntua.edu.tw

\section{Abstract}

Acculturation plays an important role in cultural product design with embedded information technologies. Therefore designing culture into products will become a design approach in interaction design. Interaction design has switched focus from usability and cognitive ergonomics to the affective aspects of user interactive experience. For cultural product design, we need a better understanding of acculturation in human-culture interaction not just for taking part in the cultural context, but also for developing the interactive experience of users. The framework for human-culture interaction in design process proposed and discussed in this paper is of value for acculturation in cultural product design. The framework also can help designers to consider how to design "culture features" into cultural products as well as provide users with a valuable reference for understanding interactive experience in products. While cultural features become an important issue in the interactive user experience, we need a better understanding of the acculturation process not only for the designer's model, but also for that of the user. For future studies, the acculturation process between human and culture in the cultural product design is worthy of further in-depth study.

Keywords: Interaction Design; User Experience; Cultural Product Design

\section{Introduction}

Designing culture into products will be a design approach in the global market. Using Cultural features to add extra value to a product can benefit not only economic growth, but also promote unique local culture in the global market [1-3]. From the design point of view, culture plays an important role in the design field, and cross-cultural design will be a key design evaluation point in the future [4,5]. Obviously, we need a better understanding of cross-cultural communications for the global market and local design. Acculturation is a process of exchanging features that are composed of the traditional culture, cultural features, cultural objects, interface design, interaction experience, user emotion, and user response [6-8]. The most important part of this process is the user experience added in the cultural product design process and involved in emotional design considerations. Emotional design has gained popularity and broad application in product design [9]. Emotional design is a design approach to constructing relationships between user experiences and product properties in order to use these properties to design products that fulfill a user's desired experiences [10-12]. 


\section{Ergonomics International Journal}

Desmet \& Hekkert [13] had stated that experience is not a property of the product but the outcome of humanproduct interaction and the results depend on what temporal characteristics and product experiences the user brings into the interaction. Norman [9] argued that affect and emotion are not as well understood as cognition, but are both considered part of the information processing system with different functions and operating parameters. Thus, how to combine emotional design and affective design to explore the human-culture interaction becomes an important issue [14]. The importance of studying culture in human product interaction design is shown repeatedly in several studies in all areas of technology design [15-19].

The growth of interest in Human-Computer Interaction (HCI) over the past decades has been extraordinary and is one of the most rapidly developing subjects in the fields of computer science and Human Factors [20]. Based on scientific research and development, we know a great deal about creating successful human - computer interaction. HCI in system design continues to make progress. In the field of interaction design between human and information technology products the cultural aspect of interaction design and affective interactive experience of users will be more broadly used in HCI. HCI has extended our understanding of interaction with information technology products and how to put this understanding to practical use in the design and evaluation of daily used products. The concept is supported by Shneiderman [21] who noted that we are now in the second transformation of computing in which the shift from machine-centered automation to usercentered services and tools is enabling users to be more creative. Beyond HCI, we need a better understanding of Human-Culture Interaction not just for taking part in the cultural context, but also for developing the interactive experience of users.

Lin, et al. [14] proposed a general framework for cultural product design that applies to the mental model of designer and user and which can be experienced in human-culture interaction. Then, the Taiwan aboriginal cultural object was taken as an example to show how to design a successful cultural product using the humanculture interaction framework. In addition, cultural ergonomics was used as an approach that considers human-culture interaction that extends our understanding of cultural meaning for design and evaluate everyday products [22].

Based on previous studies, the purpose of this paper is to extend the framework for examining the way designers interact across cultures and the interactive experience of users in the design process [23-25]. Results presented herein create a framework of human-culture interaction for examining the way designers communicate across culture as well as the interwoven experience of incorporating design and culture into the design process. Furthermore, the most important part of this a acculturation process is the user experience added in the cultural product design process and involved emotional design considerations.

\section{Cultural Product Design Model}

Based on the previous studies [26], Lin [24] proposed a model for studying cultural product design as summarized in Figure 1. It consists of three main phases: conceptual model, research method, and design process. The conceptual model focuses on how to extract cultural features from cultural objects and then transfer these features to the cultural product design. The research method is composed of three phases: identification (extract cultural features from original cultural objects), translation (transfer them to design information and design elements) and implementation to finally design a cultural product [22-24].

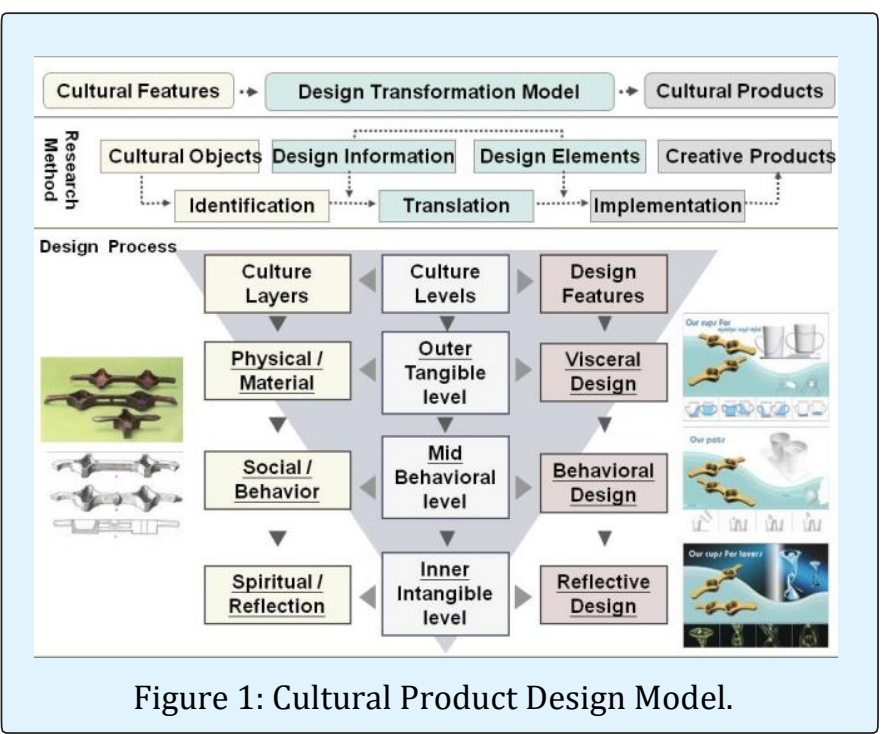

For design practice, culture can be classified into three layers: (1) Physical or material culture including food garments, and transportation related objects, (2) Social or behavioural culture including human relationships and social organization, and (3) Spiritual or ideal culture including art and religion. Since cultural objects can be incorporated into cultural design, three design features can be identified as follows: (1) the inner level containing special content such as stories, emotion, and cultural features, (2) the mid level containing function, 


\section{Ergonomics International Journal}

operational concerns, usability, and safety, and (3) the outer level dealing with colors, texture, form, decoration, surface pattern, line quality, and details [24]. Based on the cultural product design model, the cultural product is designed using scenario and story-telling approaches. In a practical design process, four steps are used to design a cultural product, namely, investigation (set a scenario), interaction (tell a story), development (write a script), and implementation (design a product) as shown in Figure 2 [24,27].

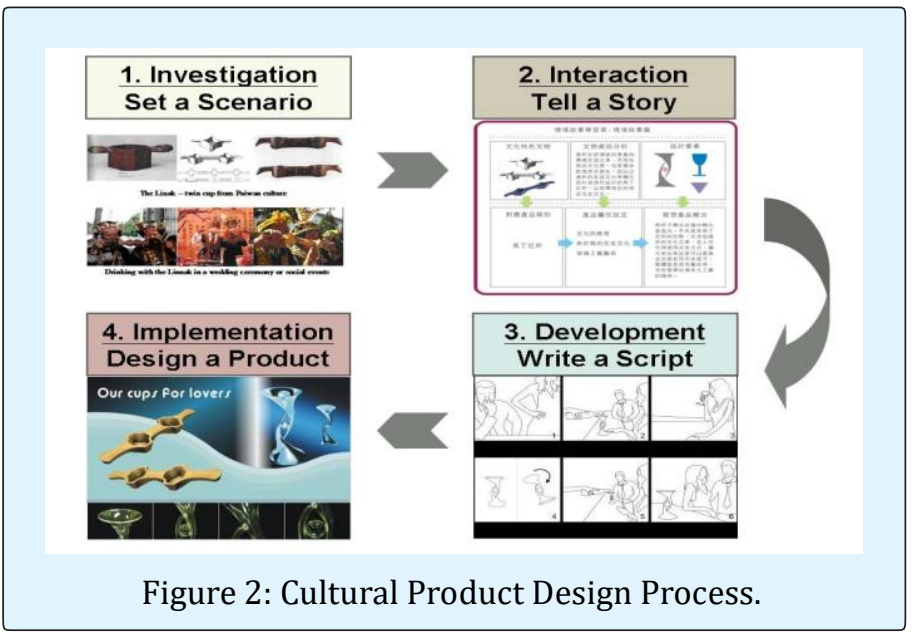

To test the utility of the cultural design process, Lin [24] took the "Linnak", a twin-cup, as the cultural object to transfer its cultural features into a modern product. The Linnak is a very typical cultural object among the Paiwan in Taiwan aboriginal culture. This cultural object represents their drinking culture and the meaning of drinking. In ancient times, Taiwan aboriginal people often drank rice wine and considered it to be a holy event. There are social meanings, cognitive ergonomic concerns and functional achievement associated with this cultural object. It contributes to a warm and sharing sprit during a festival and ceremony. To provide an ideal drinking cup derived from this aboriginal cultural object and with its warm and sharing spirit for modern market, both the social and operational interfaces of the "Linnak" need to be well-designed. The design features derived from the outer level of the Linnak deal with material, colours, form, texture, surface pattern, decoration, and details. The midlevel focuses on consumer behaviour and the scenarios in which people would use the Linnak on different occasions.

After the Linnak's appearance, usability, and cultural meaning were studied, the usage behaviour and meaning of "sharing with each other" was identified. Then, a consumer product called the "Eternity" was designed to show the culture meaning of "sharing with each other" from the original cultural object - the Linnak [25]. The "Eternity" is a symmetrical pair of cups connected together inversely to show the close relationship between the drinkers as a couple. The "Eternity" was designed as an interactive modern product to be used for example in a night club. The design concept constituted the communication between man and woman and the drinking behaviour became the mid-level relation. In the inner level of the Linnak, "sharing with each other" is transformed to communication with each other. It was romance that used the cultural object for modern social behavior as shown in the Figure $3[23,24]$.

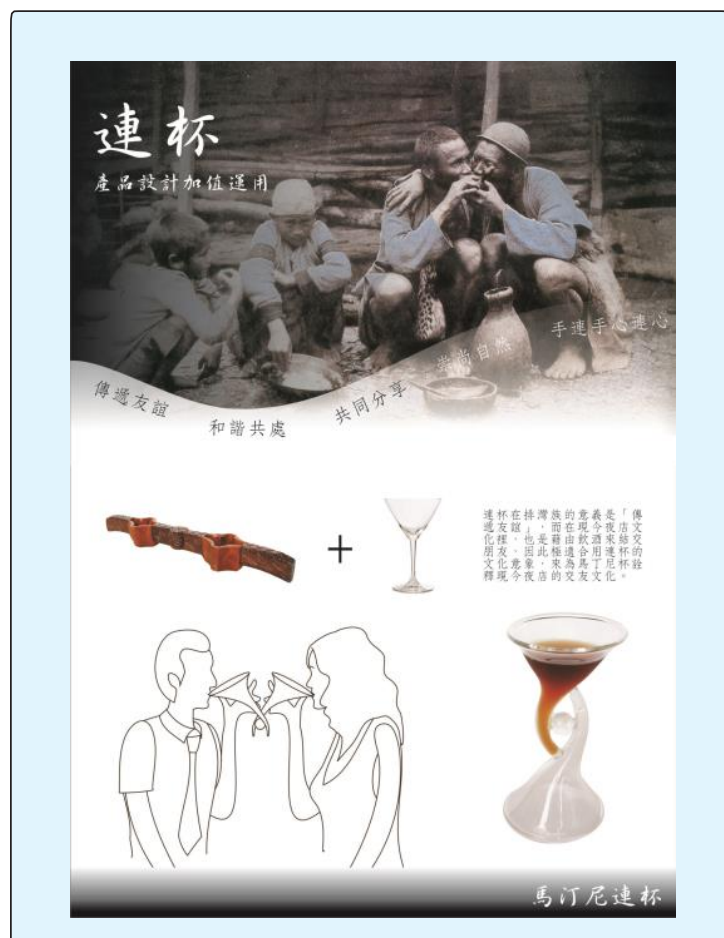

Figure 3: The Eternity - a modern twin cup.

\section{Framework for Acculturation in Human - Culture Interaction}

It is noted that people from different cultures use different types of containers to drink wine in different ways, representing different cultural meanings. Within these cultures, they may share some differences and similarities in either the hard part of handle design or soft part of cultural meaning.

The "Linnak" is a typical cultural object which can be transformed into a contemporary design for the current consumer market $[23,24]$. The contemporary consumer market may need a new form of the "Linnak" suitable for the modern environment. Thus, how to extract the idea of "sharing with each other" from Linnak in the design of the 


\section{Ergonomics International Journal}

"Eternity" is valuable for enhancing usage in our daily life. However, the Linnak may have a different emphasis in its spiritual meaning depending on the container's features and the context in which it is used, such as sharing with friends, or drinking for pleasure as showing in the Figure 4 [22]. Acculturation could play an important role in extracting the cultural features which underlie the different cultural experiences for designing a cultural product $[23,24]$. Thus, we need a framework for studying the Human-Culture Interaction to understand acculturation for the Liannk.

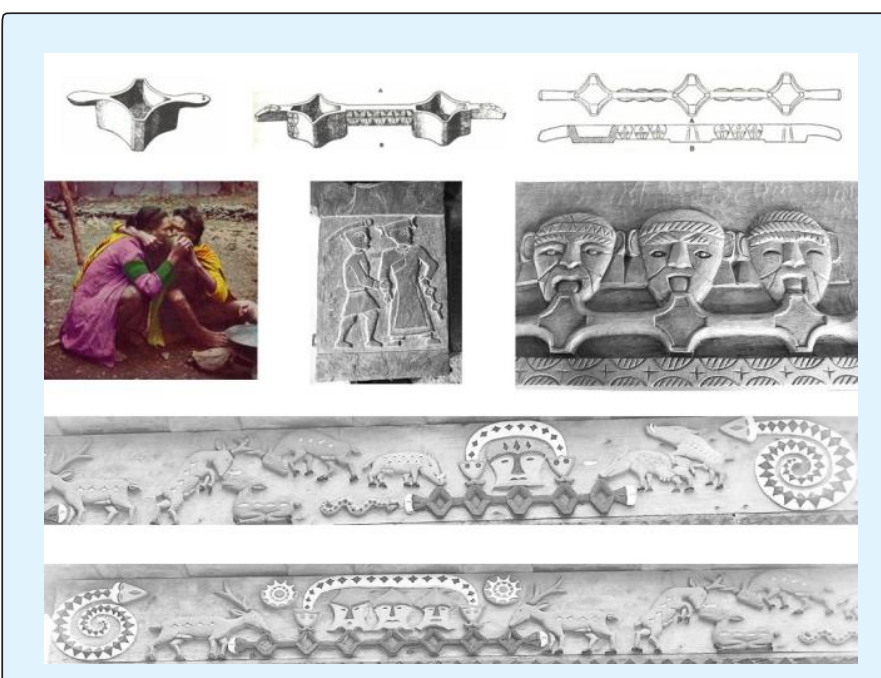

Figure 4: Different culture meanings of Linnak in sharing [22].

Based on a previous study, a framework of acculturation in Human-Culture Interaction was proposed for examining the way designers communicate across cultures as well as the cultural aspect of interaction and user experience in the design process [14]. Three levels of problems are identified in the study of human-culture interaction; technical, semantic and emotional (effectiveness) as shown in Figure 5 :

a) The technical level requires letting the desiger catch the message from cultural objects through their senses such as seeing, hearing, touching, or even feeling; that is, how the designer can accurately transmit a message through his design.

b) The semantic level requires letting the user understand the meaning of the message without misinterpreting, misunderstanding, or even not understanding it at all; that is, how precisely does the transmitted message express the derived cultural meaning.

c) The effectiveness level concerns how to inspire the user to take the right actions; that is, how effectively does the received culture meaning affect the emotional behaviors in chosing the correct actions.

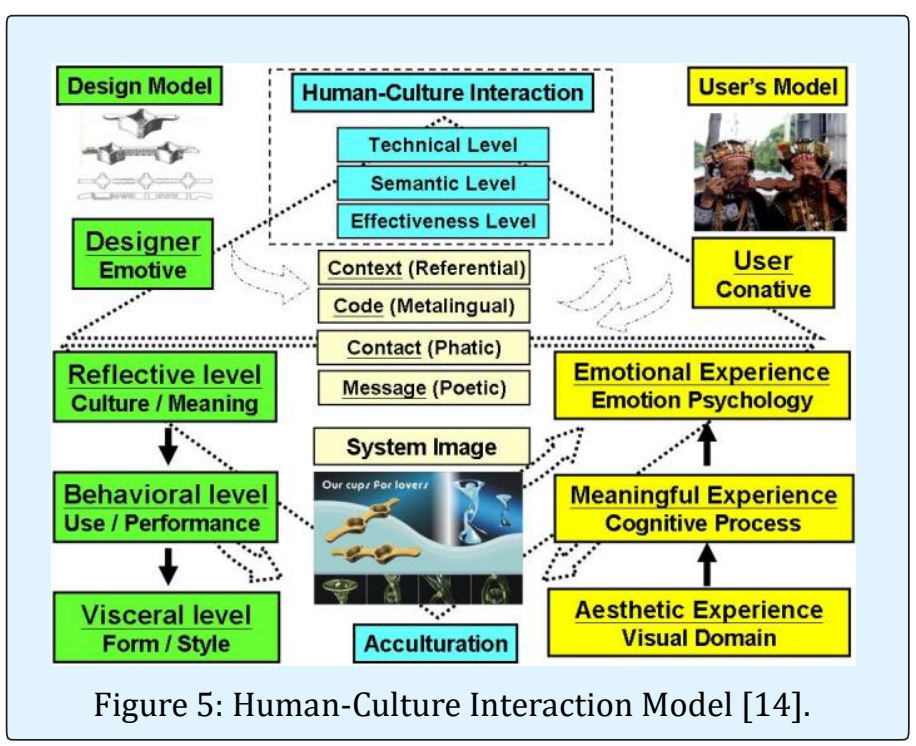

Norman [28] proposed a conceptual model which includes three parts; design model, user's model, and system image. When a designer designs a product for the user, the designer expects that the user can understand and use it in the desired way, meaning that user's model is identical to the design model. Actually, the designer should have the user's mental model rather than vice versa. The designer always understands his own design. The problem is to design a product so that it conforms to the user's mental model. The system image results from the physical structure that has been built by the design model. Because the designer does not talk directly with the user, the communication must take place through the system image. Based on communication theory, if the message (system image) does not make the design model clear and consistent, the user will end up with the wrong mental model $[14,23,24]$.

In communication theory, Jackobson [29] proposed six constitutive factors with six functions in an act of communication: designer, user, context, message, contact, and code [30]. Taking "Eternity" as an example, a designer sends a message to a user by the cultural product -Eternity. The designer recognizes that this cultural product (message) must refer to something about culture meaning other than itself which is called the background story or culture meaning (context). Then, the designer needs a physical channel and psychological connections between himself and users which is called "contact." Finally, his message must be based on a shared meaning system by which his design is structured. Each of these factors determines a different function in each act of 


\section{Ergonomics International Journal}

communication, namely; emotive, conative, referential, poetic, phatic, and metalingual. The emotive function is to communicate the designer's emotions which extract from

a cultural object all those elements that make its culture meaning unique. The other end of the process is the conative function which refers to the user's affection. The referential function is the most important part of humanculture interaction in culture meaning of "Eternity". The other three functions may appear less familiar. They are: the phatic function is to keep the channels of communication open; the metalingual function is that of identifying the code that is being used; and the poetic function is the relationship of the message to itself, as shown in Figure 5 [30,31].

For design practice, the designer focuses on the analysis of cultural meaning, operational interface, and the scenario in which the cultural object was used. System image results from the cultural features that have been redefined in order to design a cultural and aesthetical product. The user's model is the mental model developed through interaction with the cultural product. Based on the cultural context, the designer expects the user's model to be identical to the design model through the culture aspect of interaction design [23]. For the emotional design, Norman [9] proposed three levels of processing: visceral, behavioral, and reflective which are intergrated in Figure 5 as an important part of the human-culture interaction model. Using the "Eternity" as an example, the human-culture interaction is a top-down process in that the "Linnak" design features have been identified with three levels of cultural features: (1) reflective design (inner-level) which focuses on the culture meaning of "making friendship", "working together", and "sharing with each other"; (2) behavioral design (mid-level) which focuses on the consumer behavior and the scenario in which people will use the "Linnak" in what kinds of occasions; and (3) visceral design (outer-level) which focuses on the "Linnak" form factors which are associated with material, colors, texture, and pattern [22].

For the user experience, the human-culture interaction is a bottom-up process in that the user communicates directly with the cultural product: if the cultural product does not make the culture meaning clear and attractive, then the user will end up with the wrong message during the human-product interaction. There are also three levels of human-product interaction: aesthetic experience, meaningful experience, and emotional experience. The aesthetic experience involves a cultural product's form, color, texture, etc., to delight the user's sensory modalities. The experience of meaning involves the user's ability including operation, safety, etc., to assign the design features and assess user pleasure with the cultural product. The emotional experience involves user emotion including self-image, personal satisfaction, memories, etc., which are elicited by the cultural objects and designed into the cultural product $[9,23,24]$.

\section{Culture Meaning in Cultural Product Design}

In Lin's study [23,24], the "Eternity" demonstrates the value of Taiwan Aboriginal culture in design. After the paper was published, some comments came from many readers arguing the loss of the culture meaning of "working together" while "sharing with each other" at the same time. In Figure 2, the use scenario of "Eternity" in the night club indicated that the "Eternity" lost the culture meaning of close relationships when two people are not drinking at the same time [23]. These comments emphasize the cultural aspect of human-culture interaction design, therefore, designing the culture meaning of "sharing with each other" and "working together" at the same time into the "Eternity" became an important issue in the cultural product design process. Rethinking the concept of acculturation in the Linnak, the relationship between the culture meaning and "Eternity" was analyzed as shown in Figure 6. Then, based on the human-culture interaction model, the structure of the "Eternity" and the user experience and comfort considerations was redesigned. A special joint device was designed for transforming three usage forms: the standard form of cups up and down; the turning form via the rolling ball; and the two cups side by side. The refined version of designing "close relationships" into "Eternity" was developed as shown in Figure 7 [23].

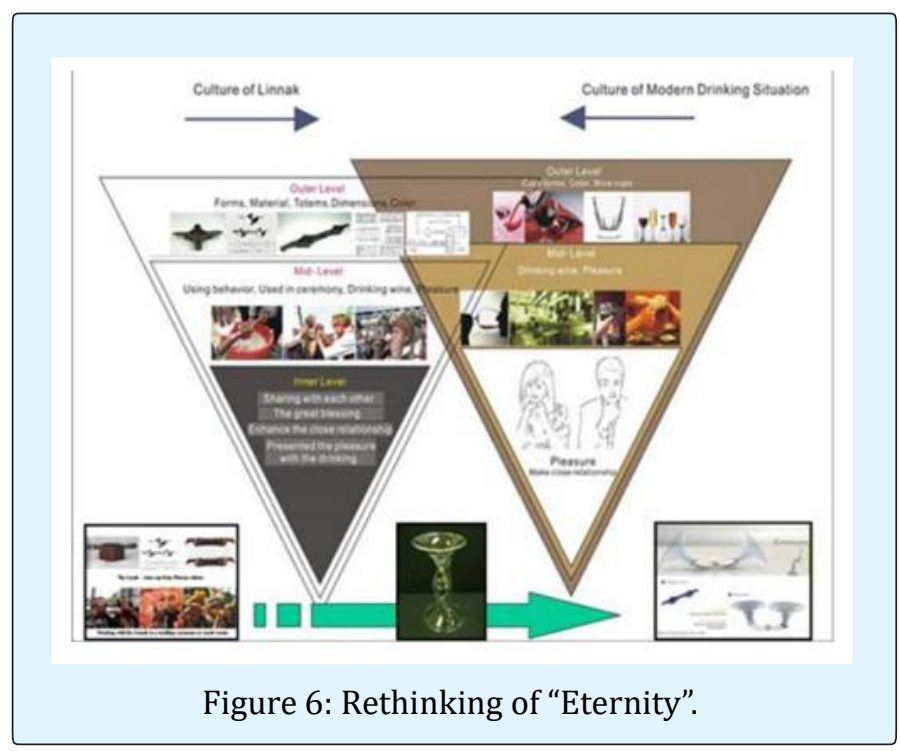




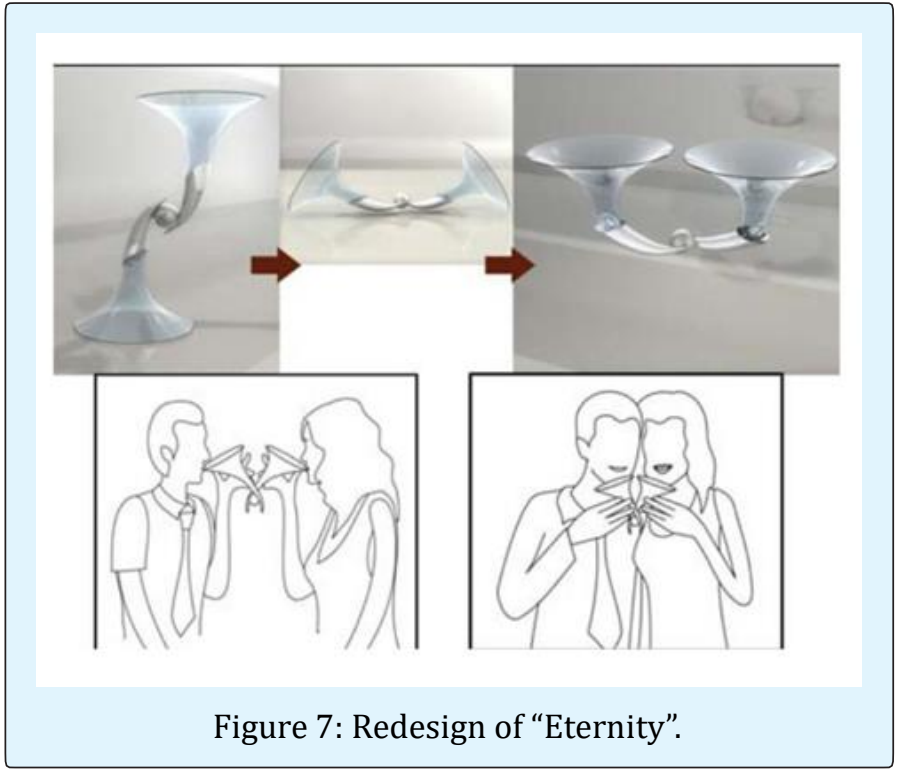

In testing user experience, the users stated that "positive relationship with the partner will make them take the two cups closely." According to user response, a metal device joining the glass-body of cups was proposed to transform the cup form and fit the different relationships and drinking situations. The transforming rolling ball device for fitting different drinking situations was retained. For usability considerations, a new handle part at the side of the cup edge, and making the edge of cup thick and solid to become the holder [23] were added. Following the scenario of using "Eternity" at a night club, in which the man wants to develop a relationship with a lady using just the standard form of "Eternity", subjects communicated developing relationship with their friends. When the "Eternity" bridges close relationships, then the next step is to use the ball (in the middle of the two cups) as a pivot and turn the bottom cup to a traditional Linnak as shown in Figure 7. In this way, the couple can drink together at the same time, side by side, shoulder by shoulder, or even face to face to show how intimate they are!

\section{Acculturation in Cultural Product Design}

Human-culture interaction is a process of acculturation which explains the process of cultural and psychological change that results following meeting between cultures $[6,7,32]$. The effects of acculturation in the human-culture interaction can be seen at designer and user levels in both interacting cultures. At the designer level, acculturation often results in changes to culture, customs, and social institutions. Noticeable designer level effects of acculturation often include changes in appearance, function and life style. At the user level, differences in the way individuals acculturate have been shown to be associated not just with changes of cultural product in daily behavior, but with the change of psychological and physical in culture meaning $[10,33]$. The designer model is used to describe the process of first-culture interacting which is the top-down process of ideation from reflecting, and behavioral study, to visceral design. Acculturation can be thought of as second-culture learning for the user which is the bottom-up process of interactive experience from aesthetic, meaningful and emotional experience.

After human-culture interaction, cultural influences come into cultural product design, such that the cultural product concepts created by designers are partly shaped by their own cultural values which caused the diversity in cultural product design. Taking the "Linnak" as an example, the following "Linnak" related cultural products were designed.

- Our Glove - from outer-level of the Linnak: An oven glove is an insulated glove usually worn in the kitchen to easily protect the wearer's hand from hot objects such as ovens, stoves, cookware, etc. Based on the cultural meaning of "Linnak", our gloves are designed by combining the function of "working together" and the feeling of "sharing with each other" as shown in Figure 8. Our gloves are designed singly for the wife or husband in a pair to be worn at the same time to show their working together and sharing with each other to enhance their feeling in the kitchen. Figure 9 shows the different designs of our gloves [23-25].

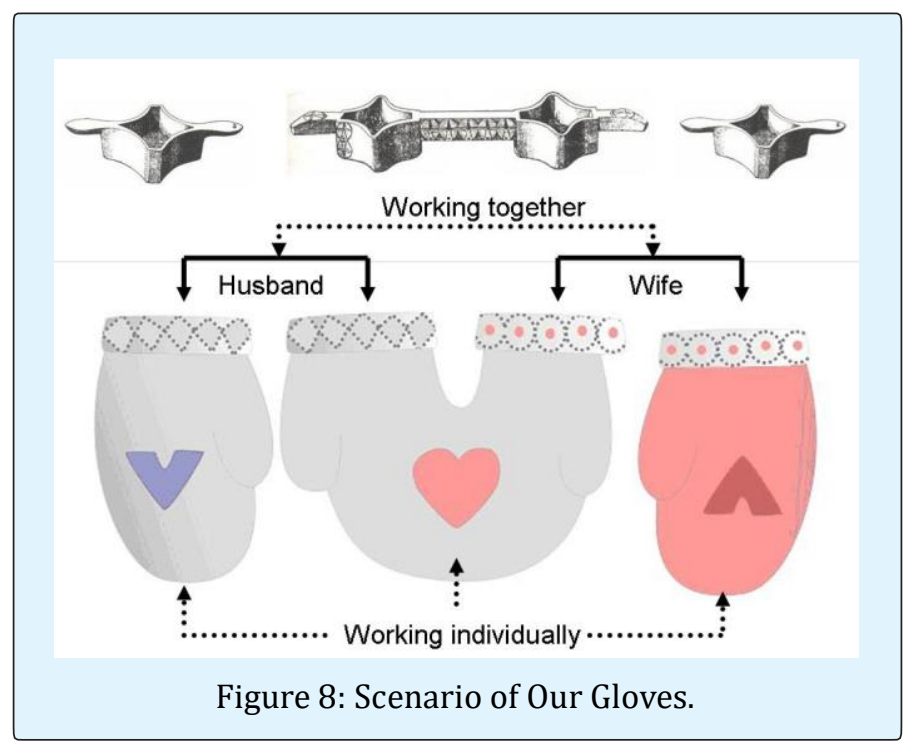




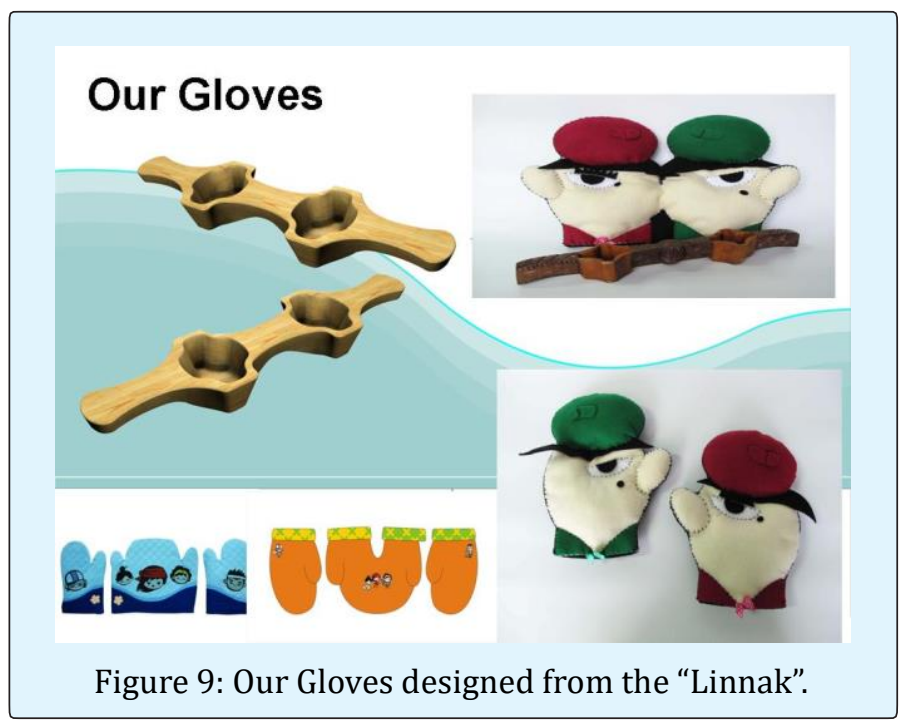

- Our Cups - from outer-level of the Linnak: Based on the cultural meaning of the "Linnak", Our Cups set was designed to show the close relationship between mother and child. In Figure 10, the main idea of Our Cups set emphasized the handles. From the usability point of view, the small cup with two handles was designed for a child learning how to use the cup to drink water easily, and the big cup with one handle was designed for the mother. When the two cups are not in use, the cups connected by the handles represent the close relationship between mother and child [23-25]. Figure 11 shows the different designs of Our Cups.

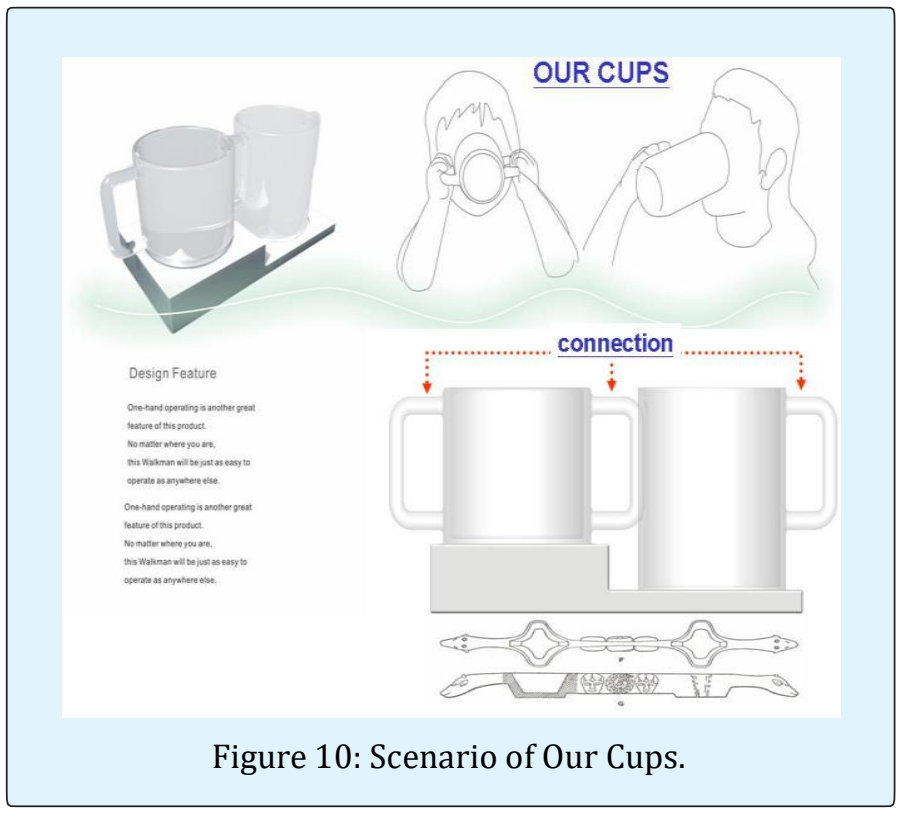

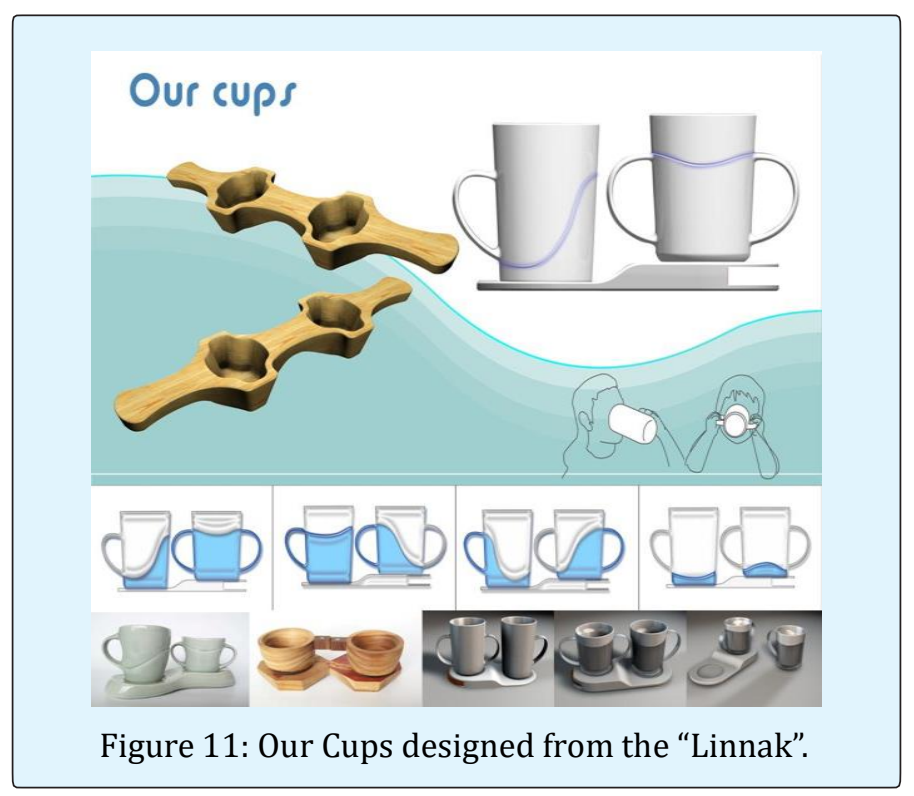

Our Pots - from inner-level of the Linnak: The main idea for Our Pots came from the inner meaning of the "Linnak" for respecting nature. If you have cultivated plants in the office, after drinking water you shared the water with the plants showing the close relationship between human and plants. Furthermore, this application of new material and technology can bring a creative form to enhance the traditional cultural value in modern society [23-25]. Figure 12 and 13 shows the scenario of Our Pots and designed from the "Linnak."

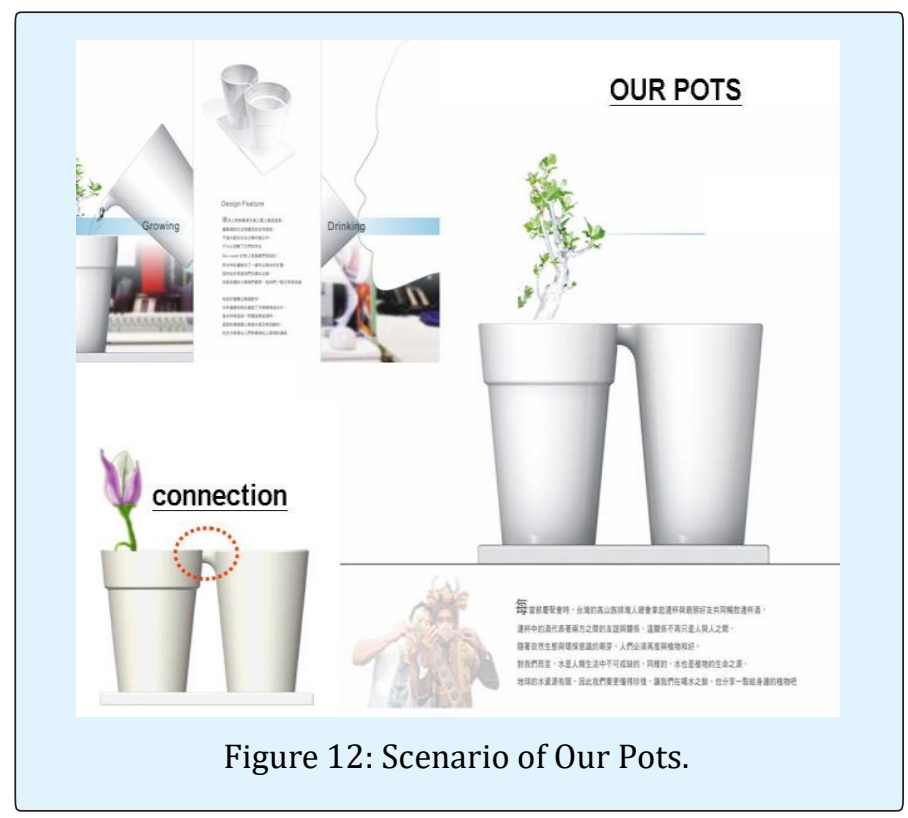




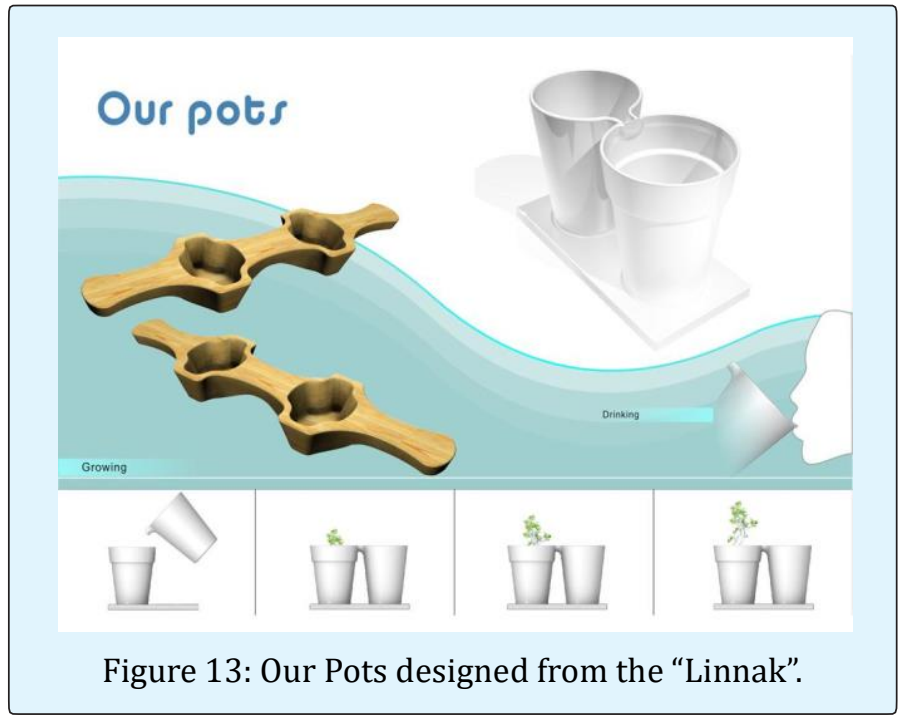

Cross-cultural product design has demonstrated important links between cultural context and cultural product development which concerns the creation, diffusion, and consumption of cultural products [10]. From the design point of view, glocalization is the trend of product design in finding difference from similarity under the concept of globalization and localization. The globalization of the economy is leading to encountering greater diversification among user groups. Product designers will therefore have to take account of the cultural differences between these user groups. With the development of the global market, most companies gradually realize that the keys to product innovation are not only market and technology aspects but also emotional design. Users' emotional response is derived from their perception of cultural attributes expressed by products playing a significant role in their visual appearance. For the local features, localization integrates the product into both the life style and the local culture of the intended region [34,35]. To be successful in localization, designers must pay particular attention to the human-culture interaction and life style of the consumer and to design the culture meaning into the product itself. Through human-culture interaction, and due to the fusion of cultures of similar nature, the consumer can become familiarized with a more diversified and wider local culture [2].

The culture of drinking wine is a very common social event in human society around the world and presents the emotional communication of user experiences. From the primitive behavior of human beings, the social events of drinking wine culture proceeded constantly and wine related products became popular daily products in the design fields. The "Eternity" presented in this study provides a good example of applying cultural features to interaction design while still retaining a meaningful cultural value. Taking "Eternity" as an example, this paper demonstrated the cultural features of "Linnak" found in three culture levels and how to transform those cultural features of interactive experiences into a new cultural product design which can fit into the contemporary market. Figure 14 shows the same cultural object - the Linnak - that inspired different cultural product designs through human-culture interaction.

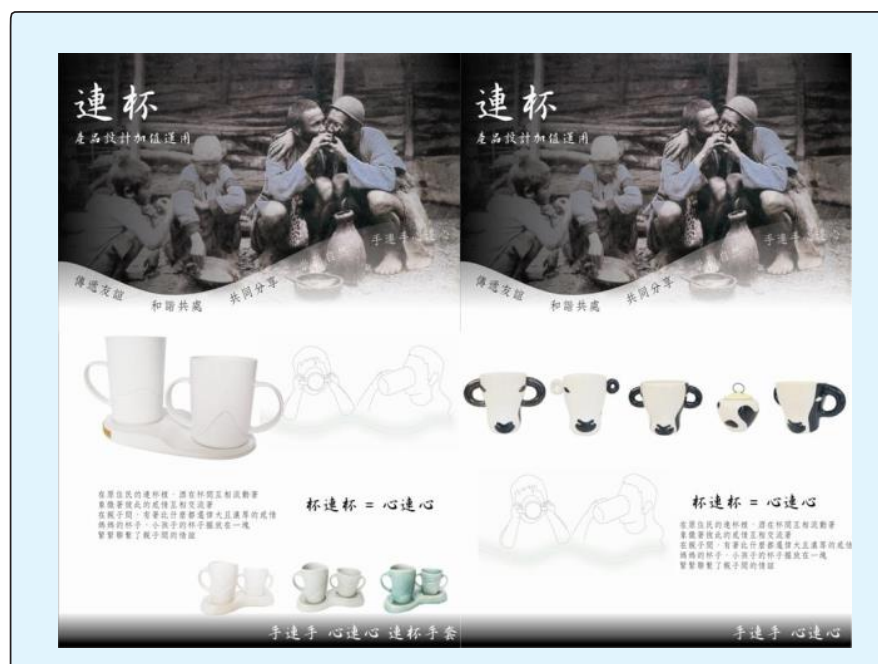

Figure 14: Various cultural products designed from the Linnak.

\section{Conclusion}

The framework of human-culture interaction that was proposed in this paper provides a different way of thinking about interactive experiences with acculturation. The framework is of value for designers because it can help to design "culture features" into interaction design, as well as provide users with a valuable reference for understanding interactive experience.

The "Linnak" provides a good example of applying cultural features to design while still retaining a meaningful cultural value. Taking "Linnak" as an example, this paper demonstrated the cultural features of "Linnak" found in three culture levels and how to transform those features into a new cultural product design which can fit into the contemporary market. Cultural products, hence, can extend the heritage and traditional values of Taiwan Aboriginal Culture to the consumer and increase the sense of spiritual essence in human life. Perhaps the best way to extend Taiwan Aboriginal Culture is to promote it in consumers' daily lives through impressions made by the use of products such as garments, crafts, decorations, utensils, furniture, ornaments, and packages whose designs are based on that culture. 


\section{Ergonomics International Journal}

While cultural features become important issues in the interactive experiences of users, the acculturation process between human and culture becomes a key issue in the cultural product design and is worthy of further in-depth study. We need a better understanding of the acculturation process not only for the designer, but also for that of the user. For future study, we suggest field investigations and interviews with Taiwanese Aboriginal people as well as literature review in order to accurately understand Aboriginal culture and art so as to avoid incorrect interpretation of the culture when transforming cultural features into modern product design. In addition, a detailed design process needs to be developed in order to provide designers with the specified procedures for designing cultural products in the future.

\section{Acknowledgments}

The author wish to thank the various students who designed the products presented in this paper, especially, C. H. Hsu, H. Cheng, M. X. Sun, W. H. Hsiao and E. T. Kuo, and colleagues who have contributed to this study over the years, especially, Dr. J. G. Kreifeldt and Dr. Y. T. Tsao.

\section{References}

1. Cunningham SD (2002) From cultural to creative industries: Theory, industry, and policy implications. Media international Australia incorporating culture and policy. Quarterly journal of media research and resources 102(1): 54-65.

2. Hsu CH, Chang SH, Lin R (2013) A design strategy for turning local culture into global market products. International Journal of Affective Engineering 12(2): 275-283.

3. Moalosi R, Popovic V, Hickling-Hudson A (2010) Culture-orientated product design. International Journal of Technology and Design Education 20(2): 175-190.

4. Lampel J, Shamsie J, Lant TK (2006) Toward a deeper understanding of cultural industries. The business of culture: Strategic perspectives on entertainment and media, pp: 3-14.

5. Lawrence TB, Phillips N (2002) Understanding cultural industries. Journal of management inquiry 11(4): 430-441.

6. Berry JW (2005) Acculturation: Living successfully in two cultures. International journal of intercultural relations 29(6): 697-712.
7. Phinney JS (2003) Acculturation: Advances in theory, measurement, and applied research. American Psychological Association, Washington, DC, US.

8. Schwartz SJ, Unger JB, Zamboanga BL, Szapocznik J (2010) Rethinking the concept of acculturation: implications for theory and research. American Psychologist 65(4): 237-251.

9. Norman DA (2004) Emotional Design. Basic Books, New York.

10. Barbu CM (2011) Cultural Adaptation of Products. Management \& Marketing-Craiova (1): 105-110.

11. Huang KH, Deng YS (2008) Social interaction design in cultural context: A case study of a traditional social activity. International Journal of Design 2(2): 81-96.

12. Marcus A (2006) Cross-cultural user-experience design. In Diagrammatic Representation and Inference 4045: 16-24.

13. Desmet PM, Hekkert P (2007) Framework of product experience. International Journal of Design 1(1): 5766.

14. Lin R, Lin PH, Shiao WS, Lin S H (2009) Cultural Aspect of Interaction Design beyond HumanComputer Interaction. In Internationalization, Design and Global Development 5623: 49-58.

15. Bermingham A, Brewer J (2013) Consumption of Culture. Routledge.

16. Blom J, Chipchase J, Lehikoinen J (2005) Contextual and cultural challenges for user mobility research. Communications of the ACM 48(7): 37-41.

17. Preece J, Sharp H, Rogers Y (2015) Interaction Design-beyond human-computer interaction. John Wiley \& Sons.

18. Rowan RM (2013) Cross-Cultural Technology Design: Creating Culture-Sensitive Technology for Local Users. Huatong Sun: New York, NY: Oxford UP, 2012. 320 pp. Technical Communication Quarterly 22(2): 191-194.

19. Shen ST, Woolley M, Prior S (2006) Towards culturecentred design. Interacting with computers 18(4): 820-852.

20. Faiola A (2007) The Design Enterprise: Rethinking the HCI Education Paradigm. Design Issues 23(3): 3045 . 
21. Shneiderman B (2002) Leonardo's Laptop: Human Needs and the New Computing Technologies. MA: MIT Press, Cambridge.

22. Lin CL, Chen SJ, Hsiao WH, Lin R (2016) Cultural ergonomics in interactional and experiential design: Conceptual framework and case study of the Taiwanese twin cup. Applied Ergonomics 52: 242252.

23. Lin R (2009) Designing friendship into modern products. In Friendships: Types, cultural, psychological and social, Nova Science 3: 1-24.

24. Lin R (2007) Transforming Taiwan aboriginal cultural features into modern product design: A case study of a cross-cultural product design model. International Journal of Design 1(2): 45-53.

25. Lin R, Sun MX, Chang YP, Chan YC, Hsieh YC, et al. (2007) Designing "culture" into modern product: a case study of cultural product design. In Usability and Internationalization 4559: 146-153.

26. Leong D, Clark H (2003) Culture-based knowledge towards new design thinking and practice - A dialogue. Design Issues 19(3): 48-58.

27. Hsu CH, Lin CL, Lin R (2011) A study of framework and process development for cultural product design. Internationalization, design and global development 6775: 55-64.
28. Norman DA (1988) The psychology of everyday things. Basic books.

29. Jakobson R (1960) Closing Statement: linguistics and poetic'. In: Sebeok T (Ed.), Style and Language, Mass: IT Press, Cambridge.

30. Jakobson R, Halle M (2002) Fundamentals of language. Walter de Gruyter.

31. Fiske J (2010) Introduction to communication studies London. Routledge.

32. Berry JW (2003) Conceptual approaches to acculturation. American Psychological Association.

33. Filson A, Lewis A (2000) Cultural issues in implementing changes to new product development process in a small to medium sized enterprise (SME). Journal of Engineering Design 11(2): 149-157.

34. Lin R, Chen CL (2012) A Discourse on the Construction of a Service Innovation Model: Focus on the Cultural and Creative Industry Park. E-BUSINESSApplication and Global Acceptance, editor Princely Ifinedo, InTech, Croatia, pp: 119-136.

35. McCracken GD (2005) Culture and consumption. Indiana University Press. 